\title{
2 \\ Cikornay National Trust: Emancipation of Our Ainu land from Colonial Land Use and for the Enjoyment of Ainu Culture
}

Kouichi Kaizawa (translated by Masumi Tanaka)

Nowadays, it seems many people are trapped in the misperception that the way to conserve forests is just to plant seedlings. But, in truth, this is not the way. I recognise that all plants grow in the most suitable place by themselves. It would be best to just let the forest be. So, why do we do planting in our forest? Planting seedlings receives a lot of attention and is seen by society as symbolic of our efforts to revitalise forest. Through Cikornay's activity, society should be able to recognise the historical facts of the colonisation of our Ainu land, as well as our hope and practice of maintaining our Ainu culture based on a balanced human-nature relationship into the future. 


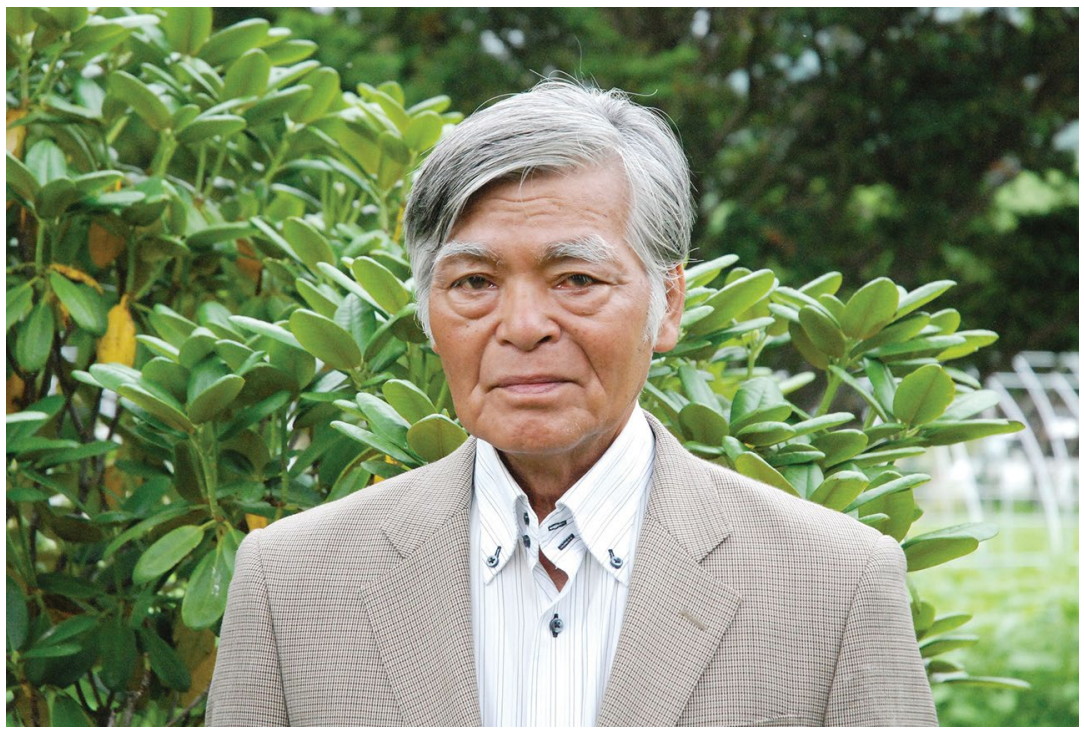

Figure 1. Kouichi Kaizawa at his home, Nibutani, Hokkaidō.

Source. Photographed by Miwako Kaizawa, 23 July 2013.

The name 'Cikornay' means 'our river' in Ainu language. When we asked the late Dr Shigeru Kayano, who devoted his life to preserving Ainu language and culture, to give a name to our organisation, he named it based on the Ainu way of thinking - that forests are always tied to rivers. Shigeru and I were the two plaintiffs for the Nibutani Dam trial, which defined the illegality of the dam and was the first official sentence to clarify the indigeneity of the Ainu. Cikornay was started in 1995, just two years before the Nibutani court decision was announced. I consider these two actions as parts of one effort to revitalise Ainu culture-opposing the Nibutani Dam construction on one hand, and conserving forest on the other.

When the Nibutani Dam construction plan was announced by the then Ministry of Construction in the 1980s, my father, Tadashi Kaizawa, and Shigeru were the only two locals who opposed the plan with legal action. When my father and Shigeru were in the legal process of opposing the dam, my father was hoping that the Japanese Government would finally listen to our Ainu voice and allow us to claim our Ainu rights. He had been taking an active political role in the then Hokkaidō Ainu Association for a long time. One day, he asked me to succeed him in opposing the dam, in case he died before the case was settled. He had never requested anything of me before that. When my father passed away in 1991, I succeeded him in the struggle, and in 1993, Shigeru and I filed the case in court. 
Cikornay's forest is located in the Nibutani community in Biratori Town of Hokkaidō, where the majority of people are Ainu. Nibutani has been my family's home place for generations. My main occupation has been farming, while also doing many other kinds of work. In the past, Ainu people were basically hunters and gathers. In the case of the Biratori area, it seems that some millet and vegetables were also grown, even before colonial policies began to coerce the Ainu into doing modern farming. At the beginning phase of the Cikornay National Trust, Cikornay's land in Nibutani was bald, with almost no trees, due to modern industrial forestry, which had operated there since after colonial imperial Japan let the big company Mitsui \& Co., Ltd exploit the local forest. When Dr David Suzuki came to Cikornay's land, he said that it looked just like a war zone.

Now, the Cikornay National Trust has registered 28 hectares in Nibutani as our land (Figure 2). In addition, in January 2015, we finished registering 2.3 hectares of donated land in Furano, around 150 kilometres from Nibutani. During the first year of Chikornay's operations in 2001, 7,500 seedlings were planted by students and volunteers. Recently, we have changed the main agenda from expanding the land by purchasing (though we still receive ceded lands) to focusing on growing, planting and caring for the seedlings of local tree species which are intensively and regularly used in the Ainu way life.

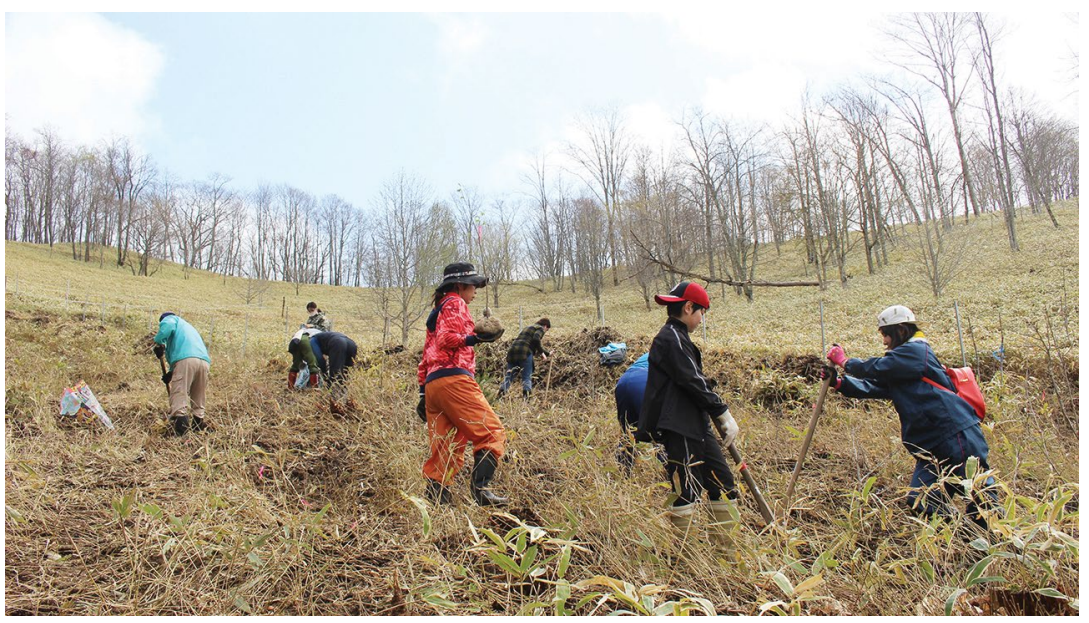

Figure 2. Cikornay National Trust's activity - planting local tree species in Nibutani.

Source. Photographed by Akemi Ooae, Nibutani, Hokkaidō, 4 May 2018. 
We are especially trying hard to produce elm tree seedlings. Elm is used for making the traditional Ainu textile called attus. In Nibutani and its surroundings, only a small number of elms are old enough to provide material for weaving. We started to grow elm trees from seeds in 2001, and finally we succeeded in growing elm seedlings after six years. However, although we have kept planting elm seedlings, almost none of them have survived so far. As one misfortune followed another, Ezo deer, which are overpopulated in Hokkaidō and which like to eat elm trees, have provided the biggest pressure on elm trees in my home area.

Cikornay is a registered nonprofit organisation under the law. It is required to have an annual general meeting, and thus we set the day of planting and the annual general meeting in early May. We schedule a two-day program. On the first day, we plant seedlings on Cikornay's lands, have the annual meeting, and also hold a get-together party at our log house. On the second day, we enjoy picking local edible plants on my family's land, while I teach about local plants and animals, and how we humans should behave in relationship to them. For example, I teach that we have to leave some of the plants at one spot, which plants are edible or poisonous, their Ainu names with meanings and related stories, and so on.

All species, including human beings, live together on the Earth. When we Ainu go to the forest, we send a prayer to tell the land that we are sorry for the disturbances caused by us taking the animals and/or plants that we need. We also apologise and ask forgiveness for taking the life from those creatures. By listening to the local Ainu Elders' experiences, I have come to understand that, traditionally, the Ainu have tried to become good friends with all beings in nature. Based on this idea, we Chikornay members try to nurture and maintain our forest. The Chikornay National Trust's future plan is to make its forest become a place where all coming to Cikornay can experience, practice and enjoy Ainu culture. For example, we could pave a footpath, set plates on each tree to show the trees' Ainu names, their meaning, and how they are used in the Ainu context, and so forth.

If we think of Ainu language revitalisation, it would be necessary to establish an Ainu territory in which the Ainu language is officially used. In 2007, the Japanese Government became a signatory to the UN Declaration on the Rights of Indigenous Peoples, so Ainu policies should be implemented based on the declaration. I do recognise that it is possible to say all the land in Hokkaidō is Ainu territory, however, I have no 
intention of claiming Ainu land rights for all of Hokkaidō, because of the reality that many non-Ainu people are living in Hokkaidō, and the land area of Japan is so tiny. Instead of that, I hope for the establishment of Ainu self-government and an area where our Ainu cultural right is fully recognised and can be enjoyed by all. If this can be realised, our culture and language will survive, even if our territory exists inside Japanese territory.

The Japanese Government and even those in the world of Japanese academia have not yet understood well the results of Indigenous studies and Indigenous policies in the international arena in terms of Indigenous peoples' collective rights. We seem to be 50 years behind places such as the Nordic countries or Canada. In the past, the country of the Ainu existed at least on Hokkaidō Island, although it was not fitted into a modern nation-state system. Since 2009, the traditional Ainu dance has been on UNESCO's Representative List of the Intangible Cultural Heritage of Humanity. It was even listed as part of Japan's intangible cultural heritage in 1984. Ainu traditional dance is normally enjoyed by a group in a community. This shows one example of the collectiveness of Ainu people. Therefore, the Japanese Government should officially recognise the collectiveness of the Ainu as a people. In addition, Ainu culture and language should be in the Japanese school curriculum, since we Ainu people have Japanese citizenship and we have a right to enjoy our Ainu culture. 
This text is taken from Indigenous Efflorescence: Beyond Revitalisation in Sapmi and Ainu Mosir, edited by Gerald Roche, Hiroshi Maruyama and Åsa Virdi Kroik, published 2018 by ANU Press, The Australian National University, Canberra, Australia.

doi.org/10.22459/IE.2018.02 